Atmos. Chem. Phys., 10, 1809-1820, 2010

www.atmos-chem-phys.net/10/1809/2010/

(C) Author(s) 2010. This work is distributed under

the Creative Commons Attribution 3.0 License.

\title{
Tracing the fate of atmospheric nitrate deposited onto a forest ecosystem in Eastern Asia using $\Delta^{17} \mathbf{O}$
}

\author{
U. Tsunogai ${ }^{1}$, D. D. Komatsu ${ }^{1}$, S. Daita ${ }^{1}$, G. A. Kazemi ${ }^{1}{ }^{1}$, , F. Nakagawa ${ }^{1}$, I. Noguchi ${ }^{2}$, and J. Zhang ${ }^{3}$ \\ ${ }^{1}$ Earth and Planetary System Science, Faculty of Science, Hokkaido University, Sapporo, Japan \\ ${ }^{2}$ Hokkaido Institute of Environmental Sciences, Sapporo, Japan \\ ${ }^{3}$ Graduate School of Science and Engineering, University of Toyama, Toyama, Japan \\ *now at: Faculty of Earth Sciences, Shahrood University of Technology, Shahrood, Iran
}

Received: 9 October 2009 - Published in Atmos. Chem. Phys. Discuss.: 2 November 2009

Revised: 2 February 2010 - Accepted: 7 February 2010 - Published: 16 February 2010

\begin{abstract}
The stable isotopic compositions of nitrate in precipitation (wet deposition) and groundwater (spring, lake, and stream water) were determined for the island of Rishiri, Japan, so as to use the ${ }^{17} \mathrm{O}$ anomalies $\left(\Delta^{17} \mathrm{O}\right)$ to trace the fate of atmospheric nitrate that had deposited onto the island ecosystem, which is a representative background forest ecosystem for eastern Asia. The deposited nitrate had large ${ }^{17} \mathrm{O}$ anomalies with $\Delta^{17} \mathrm{O}$ values ranging from $+20.8 \%$ o to $+34.5 \%$ o $(n=32)$ with $+26.2 \%$ o being the annual average. The maximum $\Delta^{17} \mathrm{O}$ value of $+34.5 \%$, obtained for precipitation on the 23rd to 24th of February 2007, was an extraordinarily large value among values for all samples of precipitation in Rishiri. Most nitrate in the sample might have been produced via $\mathrm{NO}_{3}$ radical in a highly polluted air mass that had been supplied from megacities on the eastern coast of the Asian continent. On the other hand, nitrate in groundwater had small $\Delta{ }^{17} \mathrm{O}$ values ranging from $+0.9 \%$ to $3.2 \%$ o $(n=19)$, which corresponds to an mixing ratio of atmospheric nitrate to total nitrate of $(7.4 \pm 2.6) \%$. Comparing the inflow and outflow of atmospheric nitrate in groundwater within the island, we estimated that the direct drainage accounts for $(8.8 \pm 4.6) \%$ of atmospheric nitrate that has deposited on the island and that the residual portion has undergone biological processing before being exported from the forest ecosystem.
\end{abstract}

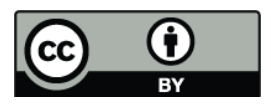

Correspondence to: $\mathrm{U}$. Tsunogai (urumu@mail.sci.hokudai.ac.jp)

\section{Introduction}

Anthropogenic activities have increased emissions of fixed nitrogen from land to the atmosphere. The amount has almost doubled globally, with much greater increases in some regions, and this fixed-nitrogen flux is expected to again double by 2030 (Galloway et al., 2008). In particular, the increase in $\mathrm{NO}_{\mathrm{x}}$ emissions in eastern Asia have been dramatic over the last decade (Akimoto, 2003; Zhang et al., 2007; Uno et al., 2007) owing to rapid growth in both industry and the number of automobiles. Most of the $\mathrm{NO}_{\mathrm{x}}$ is transported eastward by the Asian monsoon and is deposited in the area of the western north Pacific, which includes Japan, as atmospheric nitrate $\left(\mathrm{NO}_{3}^{-}(\mathrm{atm})\right)$ (Akimoto, 2003; Uno et al., 2007).

Excess fixed-nitrogen input is linked to various environmental problems such as forest decline (e.g. Fenn et al., 1998), degradation of groundwater quality (e.g. Murdoch and Stoddard, 1992; Williams et al., 1996), eutrophication of the hydrosphere (e.g. Paerl, 1997; Duce et al., 2008), and shifts in biodiversity (e.g. Tilman et al., 1996). Past detailed studies on forested catchments offered considerable insight into the link between the atmospheric deposition and the transport of nitrate to streams (Grennfelt and Hultberg, 1986; Williams et al., 1996; Tietema et al., 1998). Although water chemistry has been routinely measured through many programs on a regional to national scale, our understanding of the mechanisms that regulate the transport of atmospheric deposition to streams in forested ecosystems is still limited because the fate of atmospheric nitrate deposited onto a forest is complicated; the fate is determined through an interplay of several processes such as (1) dilution through nitrification, (2) uptake

Published by Copernicus Publications on behalf of the European Geosciences Union. 
by plants or microbes, and (3) decomposition through denitrification.

The natural stable isotopic compositions of nitrate have been used to determine the sources of nitrate in natural stream/spring water systems (Burns and Kendall, 2002; Campbell et al., 2002; Durka et al., 1994; Ohte et al., 2004; Williard et al., 2001). In particular, the oxygen isotopic compositions of nitrate can be a useful tracer of $\mathrm{NO}_{3}^{-}(\mathrm{atm})$ because $\mathrm{NO}_{3}^{-}(\mathrm{atm})$ has distinctly larger $\delta^{18} \mathrm{O}$ values than does nitrate originating from microbial processing (i.e., nitrification) in forest soils (Durka et al., 1994), where $\delta^{18} \mathrm{O}=R_{\text {sample }} / R_{\text {standard }}-1$ and $R$ is the ${ }^{18} \mathrm{O} /{ }^{16} \mathrm{O}$ ratio (or the ${ }^{17} \mathrm{O} /{ }^{16} \mathrm{O}$ ratio in the case of $\delta^{17} \mathrm{O}$ or the ${ }^{15} \mathrm{~N} /{ }^{14} \mathrm{~N}$ ratio in the case of $\delta^{15} \mathrm{~N}$ ) of the sample and each international standard. However, it is not always straightforward to quantify $\mathrm{NO}_{3}^{-}(\mathrm{atm})$ in total nitrate pool applying the isotopic mass balance model for the $\delta^{18} \mathrm{O}$ or $\delta^{15} \mathrm{~N}$ tracer, especially for those having mixing ratios of $\mathrm{NO}_{3}^{-}(\mathrm{atm})$ to total nitrate of less than $20 \%$, because of the wide range of variation in $\delta^{18} \mathrm{O}$ (or $\delta^{15} \mathrm{~N}$ ) values even within the representative sources of $\mathrm{NO}_{3}^{-}$(e.g. Michalski et al., 2004). In addition, subsequent isotopic fractionation processes in soils, such as denitrification and/or uptake by plants or microbes, could alter $\delta^{18} \mathrm{O}$ values of nitrate, complicating their interpretation beyond that of the simple isotope mass balance approach.

To overcome the limitation in using the $\delta^{18} \mathrm{O}$ tracer, Michalski et al. (2004) applied $\delta^{17} \mathrm{O}$ of nitrate as an additional tracer of $\mathrm{NO}_{3}^{-}(\mathrm{atm})$ in stream water in a complex semiarid ecosystem in southern California (USA). $\delta^{17} \mathrm{O}$ was used because remineralized nitrate $\left(\mathrm{NO}_{3}^{-}(\mathrm{re})\right)$, the oxygen atoms of which are derived from either terrestrial $\mathrm{O}_{2}$ or $\mathrm{H}_{2} \mathrm{O}$ through nitrification, shows mass-dependent relative variations between $\delta^{17} \mathrm{O}$ and $\delta^{18} \mathrm{O}$, whereas $\mathrm{NO}_{3}^{-}(\mathrm{atm})$ displays an anomalous enrichment in ${ }^{17} \mathrm{O}$ reflecting oxygen atom transfers from ozone during the conversion of $\mathrm{NO}_{\mathrm{x}}$ to $\mathrm{NO}_{3}^{-}(\mathrm{atm})$ (Michalski et al., 2003). Using the $\Delta^{17} \mathrm{O}$ signature defined by the following equation (Miller, 2002; Kaiser et al., 2007), we can distinguish $\mathrm{NO}_{3}^{-}(\mathrm{atm})\left(\Delta^{17} \mathrm{O}>0\right)$ from the other nitrate $\left(\mathrm{NO}_{3}^{-}(\mathrm{re})\right)\left(\Delta^{17} \mathrm{O}=0\right)$.

$\Delta^{17} \mathrm{O}_{\mathrm{REF}}^{X}=\frac{1+\delta^{17} \mathrm{O}_{\mathrm{REF}}^{X}}{\left(1+\delta^{18} \mathrm{O}_{\mathrm{REF}}^{X}\right)^{\beta}}-1$,

where the constant $\beta$ is 0.5247 (Miller, 2002; Kaiser et al., 2007). In addition, $\Delta \Delta^{17} \mathrm{O}$ is stable in mass-dependent isotope fractionation processes and so we can use $\Delta^{17} \mathrm{O}$ as a conserved tracer of $\mathrm{NO}_{3}^{-}(\mathrm{atm})$ and trace $\mathrm{NO}_{3}^{-}$(atm) irrespective of partial removal through denitrification and/or uptake reaction subsequent to deposition.

In this study, we determined $\Delta^{17} \mathrm{O}$ values of nitrate in spring, lake, and stream water on the island of Rishiri (Japan) as those representing groundwater charged by natural forested watersheds on the surface, where atmospheric fixed-N input has been low; less than $5 \mathrm{~kg} \mathrm{ha}^{-1} \mathrm{a}^{-1}$. Besides $\Delta^{17} \mathrm{O}$ values for groundwater, we determined values

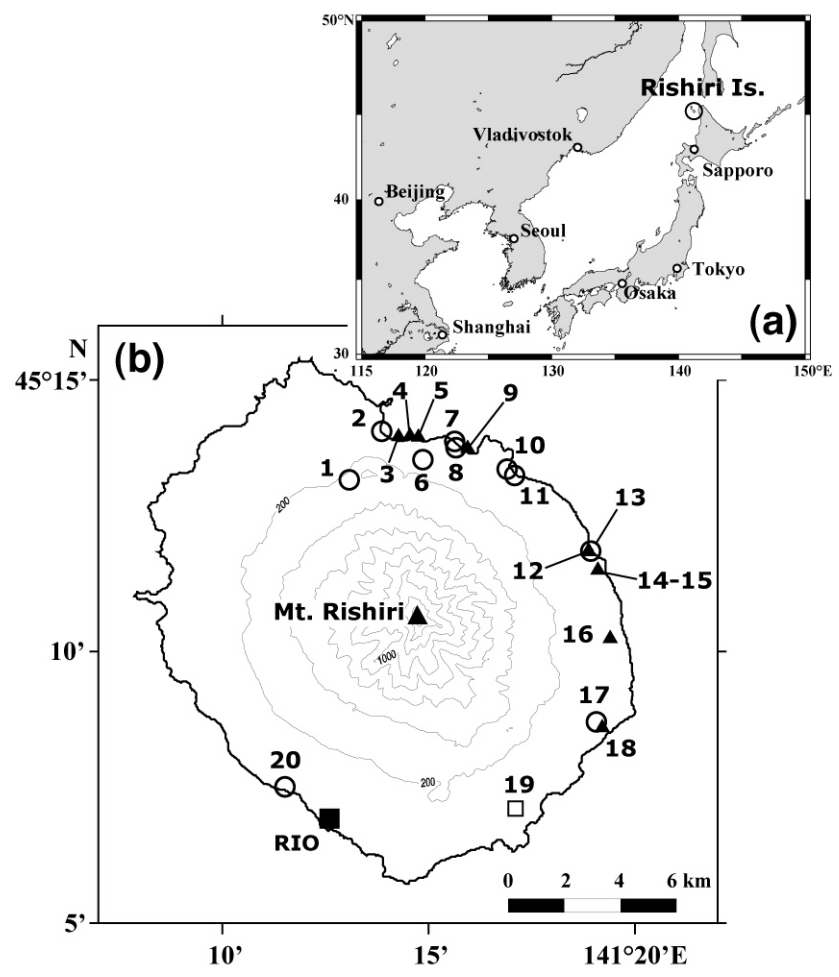

Fig. 1. Maps showing the island of Rishiri in eastern Asia (a) and the sampling stations of spring water (white circles), lake water (white square), and stream water (black triangles) on the island, together with the Rishiri National Acid Rain Monitoring Station (RIO; black square) (b). The numbers in the figure correspond to the site numbers in Table 1.

for precipitation (wet deposition) on the island for comparison. Using the $\Delta^{17} \mathrm{O}$ tracer, we quantified the fraction of $\mathrm{NO}_{3}^{-}(\mathrm{atm})$ within the total nitrate output in groundwater to gain insight into the processes controlling the fate and transport of $\mathrm{NO}_{3}^{-}(\mathrm{atm})$ deposited on the forested watershed with small anthropogenic fixed-nitrogen input. The quantified $\mathrm{NO}_{3}^{-}(\mathrm{atm})$ output will be useful in future studies to evaluate the amounts of $\mathrm{NO}_{3}^{-}(\mathrm{atm})$ eluted from the region with different $\mathrm{NO}_{3}^{-}(\mathrm{atm})$ inputs, including the amount eluted by the same forested watershed in the case of probable elevated $\mathrm{NO}_{3}^{-}(\mathrm{atm})$ input in the future.

\section{Experimental section}

\subsection{Site description}

Rishiri $\left(182.1 \mathrm{~km}^{2}\right)$ is a circular island located in the north of the Japan islands (Fig. 1). A large part of the island is occupied by the lofty volcanic Mt. Rishiri $(1721 \mathrm{~m})$, which has a conical shape with gentle slopes and the most recent eruptions of which occurred at least several thousand years ago. Little volcanic activity, including fumaroles, can be observed at present. 
One of the features of this island is that perennial streams are scarce on the surface. Instead, rain and snow-melt on the mountain, that have passed through the surface forest ecosystem without evaporation, penetrate into the rocky underground, travel downward along a horizontal slope of the subsurface hydraulic gradient as groundwater, and emerge around the shore area of the island as either terrestrial springs or submarine discharges, having a constant temperature of $(7 \pm 1){ }^{\circ} \mathrm{C}$ all year round (Yamaguchi, 1975; Yamaguchi and Ohara, 1971; Marui et al., 1999; Hayashi et al., 1999; Marui, 2003). The terrestrial springs also produce lakes and small streams around the shore area of the island. Using geochemical tracers such as tritium, chlorofluorocarbons, and $\mathrm{SF}_{6}$, the mean residence time of the groundwater in the island is estimated to be 5 to 40 years (Asai et al., 2008).

Most of the island is designated as a national park of Japan (Rishiri-Rebun-Sarobetsu National Park), so local human activities have little impact on either the hydrology or vegetation of the island. Thus, we can evaluate the background fraction of $\mathrm{NO}_{3}^{-}(\mathrm{atm})$ within the total $\mathrm{NO}_{3}^{-}$eluted from the normally forested watersheds from the groundwater of the island, which finally appears on the surface as spring, lake and/or stream water in shore areas. In addition, a monitoring observatory of the Acid Deposition Monitoring Network in East Asia (EANET) was established on the island in 2000 to quantify the acid deposition rate in background areas of eastern Asia (EANET, 2008; Noguchi et al., 2007). The monitoring has shown that the island received $12.7 \mathrm{mmol} \mathrm{m}^{-2} \mathrm{a}^{-1}$ of $\mathrm{NO}_{3}^{-}$and $19.3 \mathrm{mmol} \mathrm{m}^{-2} \mathrm{a}^{-1}$ of $\mathrm{NH}_{4}^{+}$on average from 2000 to 2007 (EANET, 2008), which corresponds to a small total fixed-N deposition rate of $4.5 \mathrm{~kg} \mathrm{ha}^{-1} \mathrm{a}^{-1}$.

In addition, the vegetation on the island had been well recorded through extensive ecological studies performed in 1977, 1979 and 2003 (Haruki et al., 2004). The forest on the island comprises Picea glehnii, P. jezoensis, Abies sachalinensis, Betula ermanii, Alnus maximowiczii and Pinus pumila.

\subsection{Sampling}

Water samples were gathered from most of the major natural springs, lakes, and streams on the island (Table 1 and Fig. 1). After measuring both $\mathrm{pH}$ and conductivity, the samples were collected in clean polyethylene bottles in the field, rinsed at least twice with the sample itself, and then filtered through a pre-combusted Whatman GF/F filter $(0.7 \mu \mathrm{m}$ pore size) within two days of collection. In addition, commercial mineral drinking water taken from a well at a Meisui factory (site number 10 in Fig. 1), filtered through a $0.2 \mu \mathrm{m}$ filter, and bottled in polyethylene terephthalate (PET) bottles on different days from July 2007 to March 2009 were collected from markets in Sapporo (sample numbers 5-8; Table 1) and used as spring water samples on days when actual spring samples were not taken (Tsunogai and Wakita, 1995).
Samples of wet deposition were taken at the Rishiri National Acid Rain Monitoring Station (RIO; Tanimoto et al., 2000) located in the south of the island $\left(45^{\circ} 7^{\prime} 11^{\prime \prime} \mathrm{N}\right.$, $141^{\circ} 12^{\prime} 33^{\prime \prime}$ E; Fig. 1) at $40 \mathrm{~m}$ above sea level using standard methods for evaluating acid deposition in Japan. An automatic wet deposition sampler (DRS-200, DKK) with a funnel (200 $\mathrm{mm}$ diameter) and a heater for melting snow deposition was used in the collection. All samples deposited on the funnel were introduced and stored within a polyethylene bottle $(1 \mathrm{~L})$ under refrigeration until daily recovery. After measuring both the conductivity and $\mathrm{pH}$, the recovered samples were filtered through a $0.2 \mu \mathrm{m}$ pore-size membrane filter (Dismic-25CS, ADVANTEC) and stored in a refrigerator until analysis. In this study, we regarded the isotopic compositions of nitrate in the wet deposition samples as those of total deposition (wet + dry deposition), because the dry deposition of nitrate in Rishiri occupied only $16 \%$ of the total deposition during 2006 (Ministry of the Environment, 2009).

\subsection{Analysis}

The concentration of nitrate was determined by traditional ion chromatography (EANET, 2008). To determine the stable isotopic compositions, the sample $\mathrm{NO}_{3}^{-}$was chemically converted to $\mathrm{N}_{2} \mathrm{O}$ using a method originally developed for ${ }^{15} \mathrm{~N} /{ }^{14} \mathrm{~N}$ and ${ }^{18} \mathrm{O} /{ }^{16} \mathrm{O}$ isotope ratios of seawater and freshwater nitrate (McIlvin and Altabet, 2005) with slight modification (Tsunogai et al., 2008). In brief, the procedures are as follows.

$15 \mathrm{~mL}$ sample solutions were pipetted into $20 \mathrm{~mL}$ screwcap vials with butyl rubber septum caps. All the vials had been washed by acid $(1 \mathrm{~mol} / \mathrm{l} \mathrm{HCl})$ to remove residual $\mathrm{Cd}$ prior to use. Then, $0.7 \mathrm{~g}$ of spongy cadmium was added, followed by $150 \mu \mathrm{L}$ of a $1 \mathrm{M} \mathrm{NaHCO}_{3}$ solution with a resultant $\mathrm{pH}$ of approximately 8.5. The samples were then shaken for $20-30 \mathrm{~h}$ on a horizontal shaker at a rate of 2 cycles/s. $10 \mathrm{~mL}$ quantities of the samples were then decanted into other clean $20 \mathrm{~mL}$ vials and capped tightly with Teflon-lined septum caps. After the evacuation of air in the head space and in the sample solution for $20 \mathrm{~min}$ via a needle, $0.4 \mathrm{~mL}$ of the azide/acetic acid buffer was added to each $20 \mathrm{~mL}$ vial via the needle and the mixture was shaken vigorously. Owing to the volatility and toxicity of $\mathrm{HN}_{3}$, all the reactions were performed on an original automatic reaction line. In addition, all exhaust was vented via a fume hood. After $30 \mathrm{~min}$, the solution was made basic by adding $0.2 \mathrm{~mL}$ of $6 \mathrm{M} \mathrm{NaOH}$ with a syringe and shaken to prevent residual $\mathrm{HN}_{3}$ escaping into the laboratory during subsequent isotope analysis.

The stable isotopic compositions of $\mathrm{N}_{2} \mathrm{O}$ were determined using our Continuous-Flow Isotope Ratio MassSpectrometry (CF-IRMS) system (Tsunogai et al., 2008), which consists of an original helium purge and a trap line and a Finnigan MAT 252 (Thermo Fisher Scientific, Waltham, MA, USA) with a modified Combustion III interface and Agilent 6890 gas chromatograph (Tsunogai et al., 2002, 2005). 
Table 1. Concentration and stable isotopic compositions $\left(\delta^{15} \mathrm{~N}, \delta^{18} \mathrm{O}\right.$, and $\left.\Delta^{17} \mathrm{O}\right)$ of nitrate dissolved in water samples taken at springs, a lake, and streams on Rishiri, together with related parameters.

\begin{tabular}{|c|c|c|c|c|c|c|c|c|c|c|}
\hline $\begin{array}{l}\text { Spl. } \\
\text { No. }\end{array}$ & Site name & $\begin{array}{l}\text { Site } \\
\text { No.* }\end{array}$ & Date & $\begin{array}{r}\text { Temp } \\
{ }^{\circ} \mathrm{C}\end{array}$ & $\mathrm{pH}$ & $\begin{array}{r}\text { EC } \\
\mu \mathrm{S} / \mathrm{cm}\end{array}$ & $\begin{array}{c}\mathrm{NO}_{3}^{-} \\
\mu \mathrm{mol} / 1\end{array}$ & $\begin{array}{r}\delta^{15} \mathrm{~N} \\
\% 0\end{array}$ & $\begin{array}{r}\delta^{18} \mathrm{O} \\
\% \circ\end{array}$ & $\begin{array}{r}\Delta^{17} \mathrm{O} \\
\% c\end{array}$ \\
\hline & spring & & & & & & & & & \\
\hline 1 & Reihou sp. & 20 & 27 Sep. '07 & 6.7 & 6.5 & 123 & 20.4 & -3.8 & +1.0 & +1.0 \\
\hline 2 & ibid. & 20 & 28 Sep. '07 & - & - & - & 19.6 & - & - & +0.9 \\
\hline 3 & Kiyokawa PS & 17 & 28 Sep. '07 & 6.0 & 7.0 & 81 & 17.9 & -1.4 & +0.4 & +1.8 \\
\hline 4 & Meisui factory & 10 & 28 Sep. '07 & 6.8 & 7.1 & 77 & 29.8 & -1.9 & +3.6 & +2.6 \\
\hline $5^{\$}$ & ibid. & 10 & Jul. '07 & - & - & - & 28.7 & -1.3 & +4.2 & +2.3 \\
\hline $6^{\$}$ & ibid. & 10 & Oct. '08 & - & - & - & 28.2 & -3.0 & +3.7 & +2.7 \\
\hline $7^{\$}$ & ibid. & 10 & Jan. '09 & - & - & - & 30.7 & -1.6 & +2.7 & +2.5 \\
\hline $8^{\$}$ & ibid. & 10 & Mar. '09 & - & - & - & 30.1 & -2.3 & +3.1 & +2.2 \\
\hline 9 & Sagidomari PS & 8 & 28 Sep. '07 & 5.7 & 7.1 & 73 & 35.5 & -0.7 & +1.3 & +1.4 \\
\hline 10 & Kanro sp. & 1 & 28 Sep. '07 & 6.4 & 6.9 & 97 & 9.7 & +0.5 & +5.2 & +2.0 \\
\hline 11 & Choujyu sp. & 2 & 28 Sep. '07 & 8.0 & 7.2 & 345 & 0.1 & +9.3 & +17.6 & - \\
\hline 12 & Himenuma sp. & 6 & 28 Sep. '07 & 7.0 & 6.8 & 116 & 9.1 & +0.8 & +7.2 & +3.2 \\
\hline 13 & Ochiushinai & 11 & 29 Sep. '07 & 6.2 & 6.7 & 88 & 17.6 & -1.7 & +5.2 & +3.2 \\
\hline 14 & Nishindomari sp. & 13 & 30 Sep. '07 & 6.5 & 7.0 & 89 & 7.6 & +0.4 & +5.0 & +3.0 \\
\hline 15 & $\begin{array}{l}\text { Fuyobashi-jo sp. } \\
\text { lake }\end{array}$ & 7 & 30 Sep. '07 & 6.7 & 6.9 & 102 & 16.9 & +0.4 & +2.8 & +2.1 \\
\hline 16 & Kiyokawa PS & 17 & 28 Sep. '07 & - & - & - & 23.2 & -1.7 & +1.6 & +1.9 \\
\hline 17 & lake Himenuma & 6 & 28 Sep. '07 & 12.0 & 7.4 & 76 & 0.1 & +0.8 & +18.8 & - \\
\hline 18 & $\begin{array}{l}\text { lake Otadomari } \\
\text { stream }\end{array}$ & 19 & 29 Sep. '07 & 13.9 & 5.8 & 112 & 0.2 & +4.5 & +45.0 & - \\
\hline 19 & Kokusei br. & 14 & 30 Sep. '07 & 8.1 & 7.0 & 83 & 21.4 & +1.1 & +2.0 & +2.3 \\
\hline 20 & Yusui river & 15 & 30 Sep. '07 & 7.9 & 7.2 & 86 & 14.3 & -2.6 & +1.6 & +2.3 \\
\hline 21 & Yamunai river & 18 & 30 Sep. '07 & 7.7 & 6.9 & 103 & 17.3 & -4.0 & -0.2 & +2.1 \\
\hline 22 & Osatsunai river & 16 & 30 Sep. '07 & 8.0 & 6.2 & 101 & 18.4 & +4.6 & -0.7 & +1.3 \\
\hline 23 & Minamisawa & 12 & 30 Sep. '07 & 9.1 & 6.5 & 90 & 9.8 & +3.7 & +0.2 & +1.3 \\
\hline 24 & Ichinosawa br. & 5 & 30 Sep. '07 & 7.6 & 7.1 & 118 & 9.1 & -1.1 & +0.4 & +1.4 \\
\hline 25 & Notsuka br. & 9 & 30 Sep. '07 & 8.5 & 7.2 & 97 & 14.8 & -1.6 & +0.3 & +1.6 \\
\hline 26 & Aioi br. & 3 & 30 Sep. '07 & 10.0 & 7.1 & 87 & 9.8 & +0.2 & +2.8 & +1.4 \\
\hline 25 & Yunagi br. & 4 & 30 Sep. '07 & 7.7 & 7.1 & 91 & 12.7 & -1.7 & -1.6 & +1.4 \\
\hline
\end{tabular}

- not determined

* location of each site is presented in Fig. 1.

$\$$ bottled mineral water (drinking water) manufactured at the factory.

EC: conductivity

First, about 0.1 to $5 \mathrm{~mL}$ of head space gas in each vial (containing 4 to $10 \mathrm{nmol}$ of $\mathrm{N}_{2} \mathrm{O}$ ) was sampled in a gas-tight syringe and injected to a helium sparging line via an injection port (Ijiri et al., 2003), sent through a purification port packed with Ascarite II and magnesium percholate to remove both the $\mathrm{CO}_{2}$ and residual $\mathrm{H}_{2} \mathrm{O}$, and then gathered to a final stainless steel trap immersed in liquid nitrogen. After changing the flow path, the liquid nitrogen bath was then removed to introduce the sample into a PoraPLOT-Q analytical capillary column $(0.32 \mathrm{~mm}$ i.d. $\times 50 \mathrm{~m})$ at a column oven temperature of $+30^{\circ} \mathrm{C}$, where the $\mathrm{N}_{2} \mathrm{O}$ was separated from any remaining $\mathrm{CO}_{2}$. The eluted $\mathrm{N}_{2} \mathrm{O}$ was carried continuously into a Finnigan MAT 252 isotope-ratio-monitoring mass spectrometer with a specially designed multicollector system via an open split interface to monitor isotopologues of $\mathrm{N}_{2} \mathrm{O}^{+}$at $m / z$ ratios of 44,45 , and 46 to determine $\delta^{45}$ and $\delta^{46}$. Each analysis was calibrated with a machine-working reference gas $\left(99.999 \% \mathrm{~N}_{2} \mathrm{O}\right.$ gas in a cylinder) introduced to the mass spectrometer via an open split interface according to a defined schedule to correct for subdaily temporal variations in the mass spectrometry. In addition, a workingstandard gas mixture containing $\mathrm{N}_{2} \mathrm{O}$ of known concentration (ca. $1000 \mathrm{ppm} \mathrm{N}_{2} \mathrm{O}$ in air), injected from a sampling loop, was analyzed in the same way as for the samples at least once a day to correct for daily temporal variations in the mass spectrometry. 
After the analyses based on the $\mathrm{N}_{2} \mathrm{O}^{+}$monitoring, another aliquot of head space (containing 20 to $100 \mathrm{nmol}$ of $\mathrm{N}_{2} \mathrm{O}$ ) was introduced in the same purge and trap line to determine $\Delta^{17} \mathrm{O}$ for $\mathrm{N}_{2} \mathrm{O}$ (Komatsu et al., 2008). Using the same procedures as those used in the $\mathrm{N}_{2} \mathrm{O}^{+}$monitoring mode, purified $\mathrm{N}_{2} \mathrm{O}$, eluted from the PoraPLOT-Q analytical capillary column, was introduced into our original gold tube unit (Komatsu et al., 2008) held at $780^{\circ} \mathrm{C}$ for the thermal decomposition of $\mathrm{N}_{2} \mathrm{O}$ to $\mathrm{N}_{2}$ and $\mathrm{O}_{2}$. The produced $\mathrm{O}_{2}$, purified from $\mathrm{N}_{2}$ through separation using a MolSieve 5A PLOT column, was subjected to CF-IRMS to determine $\delta^{33}$ and $\delta^{34}$ by simultaneous monitoring of $\mathrm{O}_{2}^{+}$isotopologues at $\mathrm{m} / \mathrm{z}$ ratios of 32,33 , and 34. Each analysis was calibrated with a machineworking reference gas $\left(99.999 \% \mathrm{O}_{2}\right.$ gas in a cylinder) introduced to the mass spectrometer via an open split interface according to a defined schedule to correct for subdaily temporal variations in the mass spectrometry. In addition, a workingstandard gas mixture containing $\mathrm{N}_{2} \mathrm{O}$ of known concentration (ca. $1000 \mathrm{ppm} \mathrm{N}_{2} \mathrm{O}$ in air), injected from a sampling loop attached to the sparging unit, was analyzed in the same way as for the samples at least once a day to correct for daily temporal variations in the mass spectrometry.

All $\delta$ values are expressed relative to air (for nitrogen) and VSMOW (for oxygen) in this paper. To calibrate the $\delta$ values of the sample $\mathrm{NO}_{3}^{-}$on the international scale, as well as to correct for both the isotope fractionation during the chemical conversion to $\mathrm{N}_{2} \mathrm{O}$ and the progress of the oxygen isotope exchange between the $\mathrm{NO}_{3}^{-}$-derived reaction intermediate and water (ca. 20\%), the obtained values of the samplederived $\mathrm{N}_{2} \mathrm{O}$ were compared with those of international standards. We used both USGS-34 $\left(\delta^{15} \mathrm{~N}=-1.8 \%\right.$, $\delta^{18} \mathrm{O}=-27.93 \%$ o, $\quad \Delta^{17} \mathrm{O}=+0.04 \%$ ) and USGS-35 $\left(\delta^{15} \mathrm{~N}=+2.7 \% o, \quad \delta^{18} \mathrm{O}=+57.5 \%\right.$ o, $\left.\quad \Delta^{17} \mathrm{O}=+20.88 \% o\right)$, the internationally distributed isotope reference materials for $\mathrm{NO}_{3}^{-}$, for the primary isotopic scale normalization. In addition, several local laboratory standards that had been calibrated using the internationally distributed isotope reference materials were also used for routine calibration purposes by measuring them in the same manner in which we measured the samples.

In calculating $\delta^{15} \mathrm{~N}, \delta^{18} \mathrm{O}$ or $\Delta^{17} \mathrm{O}$, we first determine those of $\mathrm{N}_{2} \mathrm{O}$ (Komatsu et al., 2008). Then the $\delta^{15} \mathrm{~N}$ and $\Delta{ }^{17} \mathrm{O}$ values were simply calibrated using calibration lines obtained from the measurements of $\mathrm{N}_{2} \mathrm{O}$ derived from the $\mathrm{NO}_{3}^{-}$standards. In the case of calculating $\delta^{18} \mathrm{O}$ for $\mathrm{NO}_{3}^{-}$, we additionally corrected for the oxygen exchange between some reaction intermediates and water to consider the cases in which the $\delta^{18} \mathrm{O}$ of the water that dissolved the standards differed from the $\delta^{18} \mathrm{O}$ of the sample water. Thus, we used the following formula to correct for $\delta^{18} \mathrm{O}$.

$\delta^{18} \mathrm{O}_{\text {nitrate }}=\frac{\left(\delta^{18} \mathrm{O}_{\mathrm{N}_{2} \mathrm{O}}-b\right)-(1-m) \times \Delta^{18} \mathrm{O}_{\text {water }}}{m}$,

where $b$ is the intercept of the standards and $m$ is the slope obtained using the standards and $\Delta^{18} \mathrm{O}_{\text {water }}$ is the $\delta^{18} \mathrm{O}$ dif- ference between the sample water and standard water. All oxygen isotopic data have an error of $\pm 0.5 \%$ o for $\delta^{18} \mathrm{O}$ and $\pm 0.2 \%$ o for $\Delta^{17} \mathrm{O}$. All nitrogen isotopic data have an error of $\pm 0.3 \%$ o for $\delta^{15} \mathrm{~N}$. All the errors were estimated from the reproducibility analyzing same solution having similar matrix compositions and similar $\mathrm{NO}_{3}^{-}$concentrations with the samples analyzed. While the chemical conversion process from $\mathrm{NO}_{3}^{-}$to $\mathrm{N}_{2} \mathrm{O}$ was responsible for the errors of $\delta^{15} \mathrm{~N}$ and $\delta^{18} \mathrm{O}$, the thermal decomposition process from $\mathrm{N}_{2} \mathrm{O}$ to $\mathrm{O}_{2}$ was responsible for the errors of $\Delta^{17} \mathrm{O}$.

Because we used the more precise power law (Eq. 1) for calculating $\Delta^{17} \mathrm{O}$, the estimated $\Delta^{17} \mathrm{O}$ values are somewhat different from those estimated based on the traditional linear approximation (Michalski et al., 2002). Please note that our $\Delta{ }^{17} \mathrm{O}$ values would be $(0.03 \pm 0.02) \%$ o lower for the groundwater nitrate and $(0.9 \pm 0.1) \%$ o higher for the atmospheric nitrate if we use the linear approximation for the calculation.

When we use the chemical conversion method to determine the stable isotopic compositions of $\mathrm{NO}_{3}^{-}$, nitrite $\left(\mathrm{NO}_{2}^{-}\right)$ in the samples also interfere in the final $\mathrm{N}_{2} \mathrm{O}$ produced (McIlvin and Altabet, 2005), so that we have to correct for the contribution to determine accurate stable isotopic compositions of sample $\mathrm{NO}_{3}^{-}$. Because the samples analyzed in this study contained little $\mathrm{NO}_{2}^{-}$showing the $\mathrm{NO}_{2}^{-} / \mathrm{NO}_{3}^{-}$ratios less than $1 \%$ for the samples of atmospheric nitrate and less than $3 \%$ for the samples of groundwater nitrate, we regarded that the interference must be minimum and used the results without any corrections.

\section{Results and discussion}

\subsection{Atmospheric nitrate}

The triple oxygen isotopic compositions $\left(\Delta^{17} \mathrm{O}\right)$ of atmospheric nitrate $\left(\mathrm{NO}_{3}^{-}(\mathrm{atm})\right)$ are plotted as a function of the sampling day (local time, +09:00 UT) in Fig. 2c, together with $\delta^{15} \mathrm{~N}$ and $\delta^{18} \mathrm{O}$ of $\mathrm{NO}_{3}^{-}(\mathrm{atm})$ in Fig. $2 \mathrm{a}$ and b. The figures shows large ${ }^{17} \mathrm{O}$ anomalies with $\Delta^{17} \mathrm{O}$ values from $+20.8 \%$ o to $+31.5 \%$ o, except for a sample taken from 23 to 24 February, 2007, which has an extraordinary large $\Delta^{17} \mathrm{O}$ value $(+34.5 \%$ o among the whole atmospheric nitrate in Rishiri (shown by arrows in Fig. 2).

The observed $\Delta^{17} \mathrm{O}$ values of $\mathrm{NO}_{3}^{-}(\mathrm{atm})$ can be understood in terms of the transfer of the isotope anomaly from $\mathrm{O}_{3}$ to $\mathrm{NO}_{3}^{-}(\mathrm{atm})$ (Michalski et al., 2003). In addition, the observed temporal variations in the $\Delta^{17} \mathrm{O}$ values reflect variations in the atmospheric formation channels of $\mathrm{NO}_{3}^{-}(\mathrm{atm})$ from NO (Michalski et al., 2003; Morin et al., 2008). Regardless of the $\mathrm{NO}_{\mathrm{x}}$ source, $\Delta^{17} \mathrm{O}$ of $\mathrm{NO}_{2}$ is a direct function of the isotope anomaly of $\mathrm{O}_{3}$ having large $\Delta^{17} \mathrm{O}$ due to rapid photochemical recycling to NO (Michalski et al., 2003; Morin et al., 2008). During the $\mathrm{NO}_{2}$ oxidation to $\mathrm{NO}_{3}^{-}(\mathrm{atm})$, an additional oxygen atom is incorporated from various source molecules depending on the $\mathrm{NO}_{2}$ oxidation 
channel (Michalski et al., 2003; Morin et al., 2008), which results in a characteristic $\Delta^{17} \mathrm{O}$ value of $\mathrm{NO}_{3}^{-}(\mathrm{atm})$. Within the $\mathrm{NO}_{2}$ oxidation channels, the reaction with $\mathrm{OH}$ produces $\mathrm{NO}_{3}^{-}(\mathrm{atm})$ with $\Delta^{17} \mathrm{O}$ values around $+17 \%$ at mid-latitude (Michalski et al., 2003; Morin et al., 2008; Morin et al., 2009). On the other hand, the reaction of $\mathrm{NO}_{2}$ with $\mathrm{O}_{3}$ produces $\mathrm{NO}_{3}^{-}(\mathrm{atm})$ with larger $\Delta^{17} \mathrm{O}$ values (Michalski et al., 2003; Morin et al., 2008; Morin et al., 2009) by once yielding the $\mathrm{NO}_{3}$ radical at night, which then reacts with hydrocarbons to give $\mathrm{NO}_{3}^{-}(\mathrm{atm})$ with $\Delta^{17} \mathrm{O}$ around $+35 \%$ at mid-latitude (Morin et al., 2009) or with $\mathrm{NO}_{2}$ to form $\mathrm{N}_{2} \mathrm{O}_{5}$, the hydrolysis of which forms $\mathrm{NO}_{3}^{-}(\mathrm{atm})$ with $\Delta^{17} \mathrm{O}$ around $+29 \%$ at mid-latitude (Morin et al., 2009).

On the basis of both the temporal variation in the depositional flux of $\mathrm{NO}_{3}^{-}(\mathrm{atm})$ and the $\Delta^{17} \mathrm{O}$ value, we estimated the annually averaged $\Delta^{17} \mathrm{O}$ of $\mathrm{NO}_{3}^{-}(\mathrm{atm})\left(\Delta^{17} \mathrm{O}_{\mathrm{avg}}\right)$ deposited on the island as $+26.2 \%$ using

$\Delta{ }^{17} \mathrm{O}_{\mathrm{avg}}=\frac{\sum_{i}\left(C_{i} \times V_{i} \times \Delta^{17} \mathrm{O}_{i}\right)}{\sum_{i}\left(C_{i} \times V_{i}\right)}$,

where $C_{i}$ denotes the concentration of nitrate in each wet deposition sample and $V_{i}$ denotes the total water volume of each wet deposition sample. Substituting $\Delta^{17} \mathrm{O}$ with $\delta^{15} \mathrm{~N}$ (or $\delta^{18} \mathrm{O}$ ) in the Eq. (3), we estimated $\delta^{15} \mathrm{~N}_{\mathrm{avg}}$ as $-1.1 \%$ and $\delta^{18} \mathrm{O}_{\text {avg }}$ as $+87.1 \%$.

The annual average $\Delta^{17} \mathrm{O}$ coincided well with annual average $\Delta^{17} \mathrm{O}$ values of $\mathrm{NO}_{3}^{-}(\mathrm{atm})$ reported for mid-latitudes, such as at La Jolla ( $33^{\circ} \mathrm{N}$; Michalski et al., 2003) and Princeton $\left(40^{\circ} \mathrm{N}\right.$; Kaiser et al., 2007). In addition, the annual average $\delta^{18} \mathrm{O}$ values of $\mathrm{NO}_{3}^{-}(\mathrm{atm})$ were in reasonable agreement with those reported recently for nitrate in deposition ( +60 to $+95 \%$ o by Michalski et al., $2004 ;+60$ to $+90 \%$ o by Morin et al., 2009). Furthermore, the seasonal variations in $\Delta^{17} \mathrm{O}$ and $\delta^{18} \mathrm{O}$ coincided well with those reported. In summer, the reaction between $\mathrm{OH}$ and $\mathrm{NO}_{2}$ is the main $\mathrm{NO}_{\mathrm{x}}$ oxidation channel. In contrast, the reaction of $\mathrm{NO}_{2}$ with $\mathrm{O}_{3}$ becomes relatively important for the production of $\mathrm{NO}_{3}^{-}(\mathrm{atm})$ in winter. While past reports on $\Delta^{17} \mathrm{O}$ of $\mathrm{NO}_{3}^{-}(\mathrm{atm})$ have been limited to the United States (Michalski et al., 2003; Michalski et al., 2004), Europe (Kaiser et al., 2007), and the Atlantic Ocean (Morin et al., 2009) at mid-latitudes, the correspondence further supports that $\Delta^{17} \mathrm{O}$ and $\delta^{18} \mathrm{O}$ values of $\mathrm{NO}_{3}^{-}(\mathrm{atm})$ are determined by $\mathrm{NO}_{\mathrm{x}}$ oxidation channels that shift depending on the season and oxidant species; for example, shifts in oxidation chemistry (an increased importance of $\mathrm{N}_{2} \mathrm{O}_{5}$ hydrolysis in winter) that vary with sunlight, temperature, and oxidant levels but not with $\mathrm{NO}_{\mathrm{x}}$ sources. The average $\Delta^{17} \mathrm{O}$ of $\mathrm{NO}_{3}^{-}(\mathrm{atm})$ is substantially higher than values resulting from the reaction between $\mathrm{OH}$ and $\mathrm{NO}_{2}(+17 \%$; Morin et al., 2009). Therefore, the reaction between $\mathrm{OH}$ and $\mathrm{NO}_{2}$ cannot be the only channel from $\mathrm{NO}_{2}$ to $\mathrm{NO}_{3}^{-}(\mathrm{atm})$, including that deposited in eastern Asia.
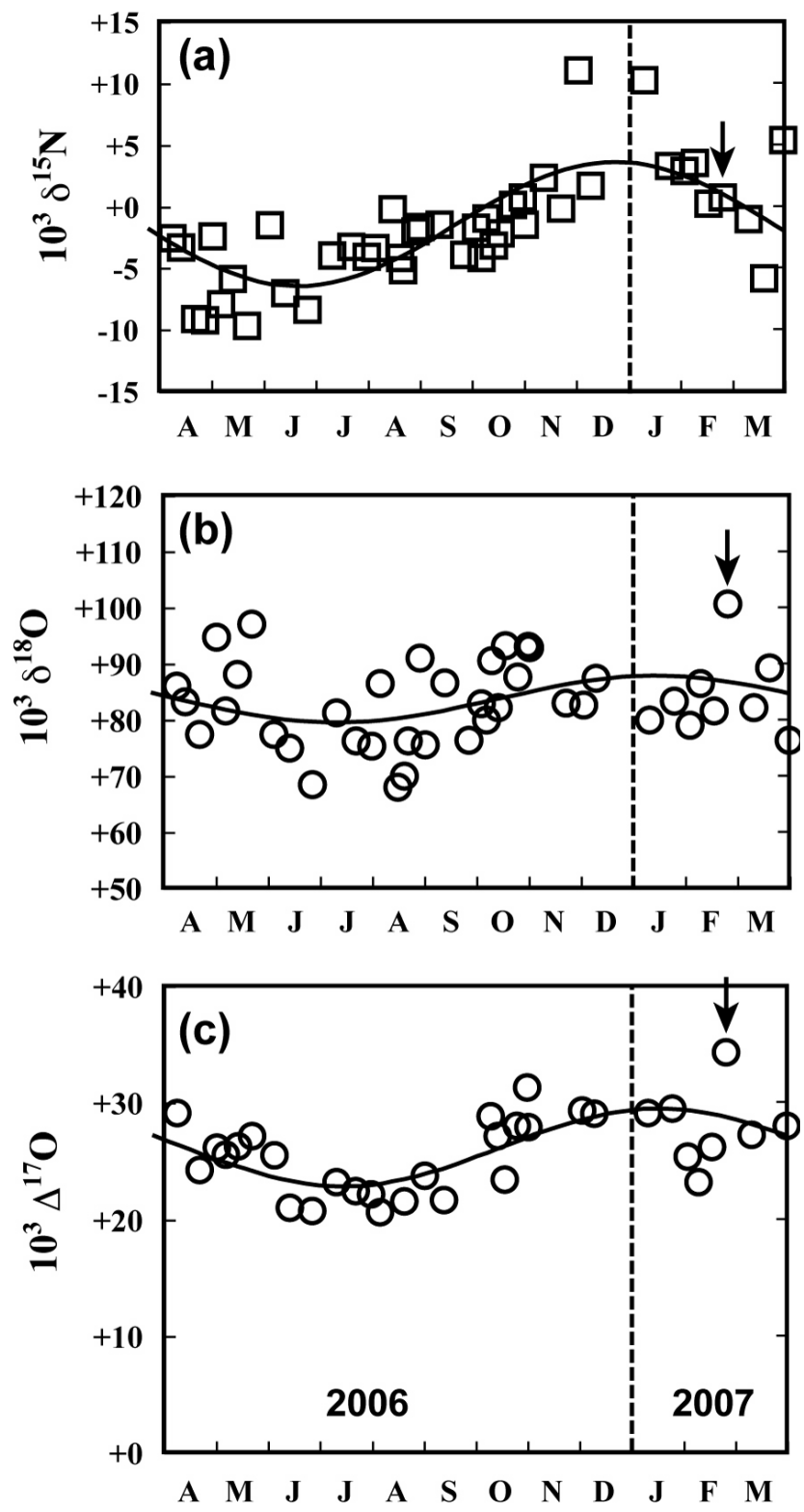

Fig. 2. Temporal variations in the values of $\delta^{15} \mathrm{~N}(\mathbf{a}), \delta^{18} \mathrm{O}(\mathbf{b})$, and $\Delta^{17} \mathrm{O}(\mathbf{c})$ of nitrate in wet deposition recorded at the Rishiri national air monitoring station. The curved lines are sinusoidal curves fitting the data assuming annual periodicity (determined using unweighted least squares). The arrows indicate sampling from 23 to 24 February 2007 (LT).

Among the $\Delta^{17} \mathrm{O}$ data of nitrate in wet deposition in Rishiri, an extraordinarily large $\Delta^{17} \mathrm{O}$ value was obtained from February 23 to 24, 2007 (local time), as indicated by arrows in Fig. 2. The $\Delta^{17} \mathrm{O}$ value $(+34.5 \%$ ) exceeded the 2 $\sigma$ variation range of whole atmospheric nitrate in Rishiri. It is difficult to produce $\mathrm{NO}_{3}^{-}(\mathrm{atm})$ with such a $\Delta{ }^{17} \mathrm{O}$ value $(+34.5 \%$ o $)$ through usual $\mathrm{NO}_{2}$ oxidation reaction channels such as the reaction between $\mathrm{OH}$ and $\mathrm{NO}_{2}$. Rather, the elevated $\Delta^{17} \mathrm{O}$ value implies that the $\mathrm{NO}_{3}^{-}(\mathrm{atm})$ is primarily 

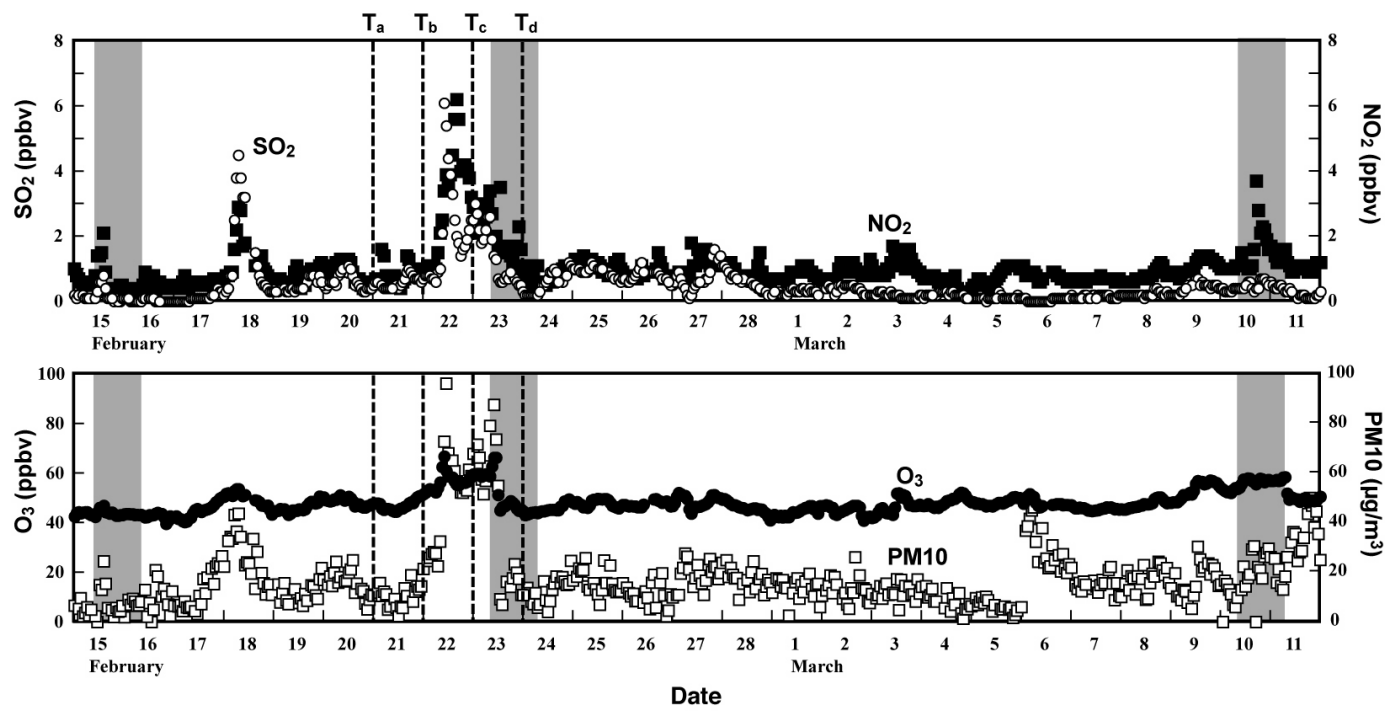

Fig. 3. Temporal variations in the atmospheric components monitored at Rishiri observatory $\left(\mathrm{SO}_{2}\right.$ : white circles, $\mathrm{NO}_{2}$ : black squares, ozone: black circles, $\mathrm{PM}_{10}$ : white squares), together with the sampling durations of wet deposition analyzed in this study (grey zones). The dotted lines $\left(\mathrm{T}_{\mathrm{a}}, \mathrm{T}_{\mathrm{b}}, \mathrm{T}_{\mathrm{c}}\right.$, and $\mathrm{T}_{\mathrm{d}}$ ) denote the initial points of backward trajectory calculated in this study (Fig. 4).

produced via $\mathrm{NO}_{3}$ radical, such as $\mathrm{N}_{2} \mathrm{O}_{5}$ hydrolysis or the $\mathrm{H}$ abstraction from hydrocarbons by the $\mathrm{NO}_{3}$ radical.

To test this hypothesis, we compared the $\Delta^{17} \mathrm{O}$ results with the other components monitored successively at the Rishiri National Acid Rain Monitoring Station and found an episodic contribution of highly polluted air-mass from 22 to 23 February until the beginning of the precipitation in which the extraordinarily large $\Delta^{17} \mathrm{O}$ value was detected (Fig. 3). The polluted air was characterized by significant enrichments in $\mathrm{SO}_{2}$ (6 ppbv), $\mathrm{NO}_{2}$ (6 ppbv), $\mathrm{O}_{3}$ (65 ppbv), and $\mathrm{PM}_{10}\left(100 \mu \mathrm{g} / \mathrm{m}^{3}\right)$ while concentrations in background air were $1 \mathrm{ppbv}, 1 \mathrm{ppbv}, 40 \mathrm{ppbv}$, and $15 \mu \mathrm{g} / \mathrm{m}^{3}$ respectively in the observatory (Fig. 3). The daily averaged concentrations in 23 February were the second largest concentration for $\mathrm{NO}_{2}$ and the third largest concentration for $\mathrm{SO}_{2}$ and $\mathrm{PM}_{10}$ among all the daily averaged concentrations within the days from April 2006 to March 2007. Besides, among all the episodic contribution events of similar polluted air-mass, the event was the only one accompanying precipitation in Rishiri. The backward trajectory analyses of air parcels (Fig. 4; Zeng et al., 2003) suggest that the polluted air was derived from the megacities on the eastern coast of Asia at latitudes of 35 to $40^{\circ} \mathrm{N}$ (Fig. 4), where air pollution is significant (e.g. Guttikunda et al., 2005). The observed large $\Delta^{17} \mathrm{O}$ values of $\mathrm{NO}_{3}^{-}$(atm) suggest an elevated role for the reaction of $\mathrm{NO}_{3}$ radical in the polluted air mass to produce $\mathrm{NO}_{3}^{-}$(atm), possibly owing to the large surface area of aerosols and/or enrichment of anthropogenic hydrocarbons within the polluted air mass. The $\mathrm{NO}_{3}^{-}$(atm) production channel involving the $\mathrm{NO}_{3}$ radical is not a significant source of $\mathrm{NO}_{3}^{-}$(atm) in the troposphere (e.g. Michalski et al., 2003; Alexander et al., 2009).
The present result implies that a future increase in air pollution could increase the importance of $\mathrm{NO}_{3}$ radical to produce $\mathrm{NO}_{3}^{-}(\mathrm{atm})$.

\subsection{Groundwater nitrate}

The concentrations and $\delta^{15} \mathrm{~N}, \delta^{18} \mathrm{O}$, and $\Delta^{17} \mathrm{O}$ values of nitrate in the samples of spring, lake, and stream water are presented in Table 1, together with their temperature, $\mathrm{pH}$ and conductivity. We could not determine $\Delta^{17} \mathrm{O}$ values of nitrate for two of the three lake water samples (Nos. 17 and 18) owing to nitrate depletion in the samples, probably due to nitrate uptake (assimilation) by phytoplankton in the lakes during stasis of seeping water in the lake. In addition, we could not determine $\Delta^{17} \mathrm{O}$ of nitrate for a spring water sample (No. 11) owing to nitrate depletion in the samples, probably due to denitrification in and/or around the well. The rest of the samples had nitrate concentrations of more than $5 \mu \mathrm{mol} / 1$, and the temperature and conductivity were similar to values of representative groundwater within the island $\left((7 \pm 1)^{\circ} \mathrm{C}\right.$ and $(100 \pm 20) \mu \mathrm{S} / \mathrm{cm}$ ) (Yamaguchi and Ohara, 1971; Hayashi et al., 1999). In further discussions to evaluate the interaction of $\mathrm{NO}_{3}^{-}$(atm) with the forest ecosystem on the island based on nitrate in groundwater, we use the data for the spring, lake, and stream water samples except for Nos. 11, 17, and 18 to represent the groundwater of the island.

The $\Delta^{17} \mathrm{O}$ data of samples taken at the same site (sample numbers 1 and 2, and from 4 to 8) on different days coincided well, within the analytical precision. We concluded that the hydrological system including the nitrogen cycle was stable on the island under a steady state condition and that the data obtained represented long-range mean values (at least of 


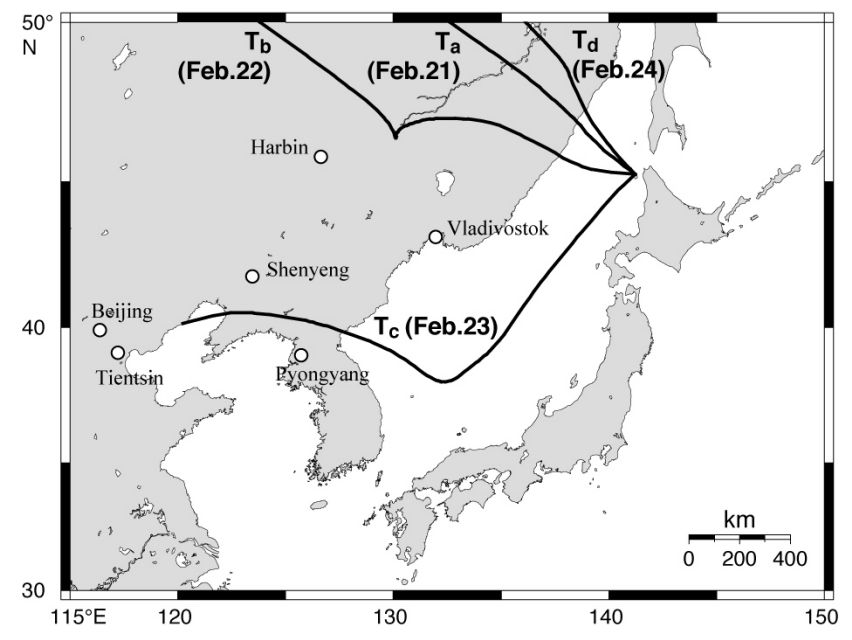

Fig. 4. The backward trajectory ( 3 days) of the air parcel reaching Rishiri at 00:00 a.m. on 23 Feb. 2007 LT (+09:00 UT), together with those reaching Rishiri on 21, 22, and 24 Feb. 2007, calculated using METEX software (http://db.cger.nies.go.jp/metex/index.html) and NCEP datasets.

annual range) for groundwater within the island. The fairly long residence times of 5 to 40 years for the groundwater within the island (Asai et al., 2008) also supports this conclusion.

All the groundwater samples in this study had small but positive $\Delta^{17} \mathrm{O}$ values ranging from +0.9 to $+3.2 \%$. The groundwater within the island contained $\mathrm{NO}_{3}^{-}$(atm) to some extent. Using the $\Delta^{17} \mathrm{O}$ data of nitrate in each sample, we estimated the mixing ratio of $\mathrm{NO}_{3}^{-}($atm $)$to total $\mathrm{NO}_{3}^{-}$ $\left(\mathrm{NO}_{3}^{-}\right.$(total)) in the groundwater to be $7.4 \%$ on average, with a range from 3.4 to $12.2 \%$, applying the equation

$$
\frac{\mathrm{C}_{\mathrm{atm}}}{\mathrm{C}_{\text {total }}}=\frac{\Delta^{17} \mathrm{O}}{\Delta^{17} \mathrm{O}_{\mathrm{avg}}},
$$

where $\mathrm{C}_{\mathrm{atm}} / \mathrm{C}_{\text {total }}$ is the mixing ratio of $\mathrm{NO}_{3}^{-}$(atm) to

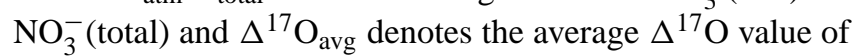
$\mathrm{NO}_{3}^{-}$(atm) estimated in the previous section $(+26.2 \%$ ).

We conclude that only $(7.4 \pm 2.6) \%$ of the total nitrate in groundwater originates directly from the atmosphere on average in Rishiri, and so the substantial remainder of nitrate is of remineralized origin $\left(\mathrm{NO}_{3}^{-}(\mathrm{re})\right)$ and has been produced through biological processing in soil. The mixing ratios estimated from $\mathrm{NO}_{3}^{-}$(atm) in the groundwater coincide well with those estimated from basic stream flows (3.1 to $7.7 \%$ ) and soil extracts (1.9 to $11.4 \%$ ) in southern California using $\Delta^{17} \mathrm{O}$ in a past study (Michalski et al., 2004), except during storms. We conclude that the mixing ratios can be considered as one of representative mixing ratios of $\mathrm{NO}_{3}^{-}$(atm) in natural $\mathrm{NO}_{3}^{-}$eluted from usual forest ecosystems. By adding more $\Delta^{17} \mathrm{O}$ data on nitrate eluted from broad forest ecosystem, we can determine more precise mixing ratio of atmo-

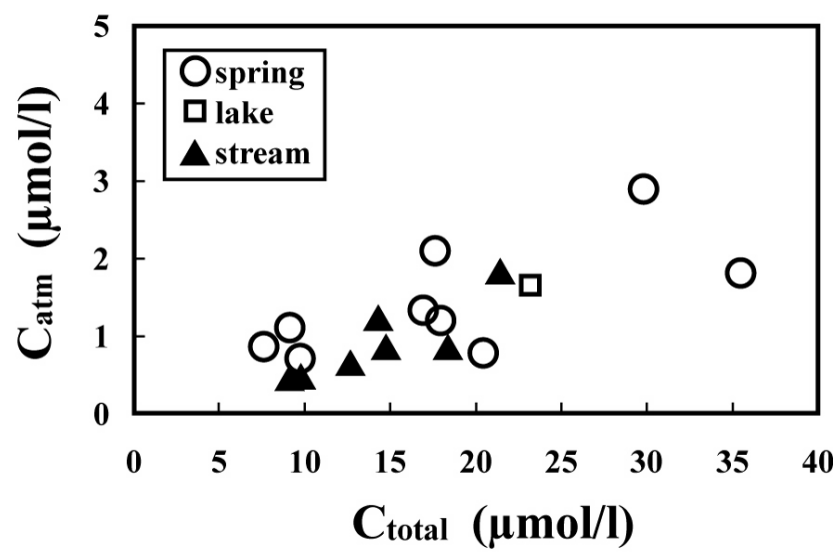

Fig. 5. Calculated concentration of atmospheric $\mathrm{NO}_{3}^{-}\left(\mathrm{C}_{\mathrm{atm}}\right)$ in each sample of spring (white circles), lake (white square), and stream (black triangles) water plotted as a function of the total $\mathrm{NO}_{3}^{-}$ concentration $\left(\mathrm{C}_{\text {total }}\right)$.

spheric nitrate in natural nitrate eluted from forest ecosystem in general.

To discuss the processes regulating the mixing ratios of $\mathrm{NO}_{3}^{-}$(atm), the absolute concentration of $\mathrm{NO}_{3}^{-}$(atm) in each sample $\left(\mathrm{C}_{\mathrm{atm}}\right)$ was calculated using each nitrate concentration $\left(\mathrm{C}_{\text {total }}\right)$ and each $\Delta^{17} \mathrm{O}$ value and employing Eq. (4). The calculated $\mathrm{C}_{\text {atm }}$ is plotted as a function of $\mathrm{C}_{\text {total }}$ for the samples in Fig. 5.

While $C_{\text {total }}$ varied widely from 7.6 to $35.5 \mu \mathrm{mol} / 1, \mathrm{C}_{\mathrm{atm}}$ was almost uniform for the samples around $1.2 \mu \mathrm{mol} / \mathrm{l}$ on average, ranging from 0.5 to $2.9 \mu \mathrm{mol} / 1$. We conclude that $\mathrm{NO}_{3}^{-}$(atm) concentrations were almost uniform within the groundwater of the island while the observed variation in the total $\mathrm{NO}_{3}^{-}$concentration is primarily due to different contributions of $\mathrm{NO}_{3}^{-}$(re). That is, additional contributions of $\mathrm{NO}_{3}^{-}$(re) during groundwater flow through the ground were responsible for the observed differences in total $\mathrm{NO}_{3}^{-}$among the groundwater samples. In addition, the present results suggest that all groundwater samples contained almost the same level of $\mathrm{NO}_{3}^{-}(\mathrm{atm})$ irrespective of the recharge area on the island, while the concentration of $\mathrm{NO}_{3}^{-}(\mathrm{atm})$ in wet deposition must be much more variable (from 1.3 to $122.2 \mu \mathrm{mol} / 1$ for the samples analyzed in this study, for instance). The $\mathrm{NO}_{3}^{-}(\mathrm{atm})$ concentration in groundwater $((1.2 \pm 0.6) \mu \mathrm{mol} / \mathrm{l})$ might represent the lowest limit for the forest ecosystem to uptake atmospheric nitrate. That is to say, $\mathrm{NO}_{3}^{-}(\mathrm{atm})$ in wet deposition had been consumed until the level in the recharge area so that we could find the almost uniform $\mathrm{NO}_{3}^{-}(\mathrm{atm})$ in groundwater.

\subsection{Post-depositional processes}

While the $\Delta^{17} \mathrm{O}$ values of nitrate are not affected by postdepositional processes such as partial removal through nitrate uptake or denitrification, the $\delta^{18} \mathrm{O}$ values of nitrate vary 


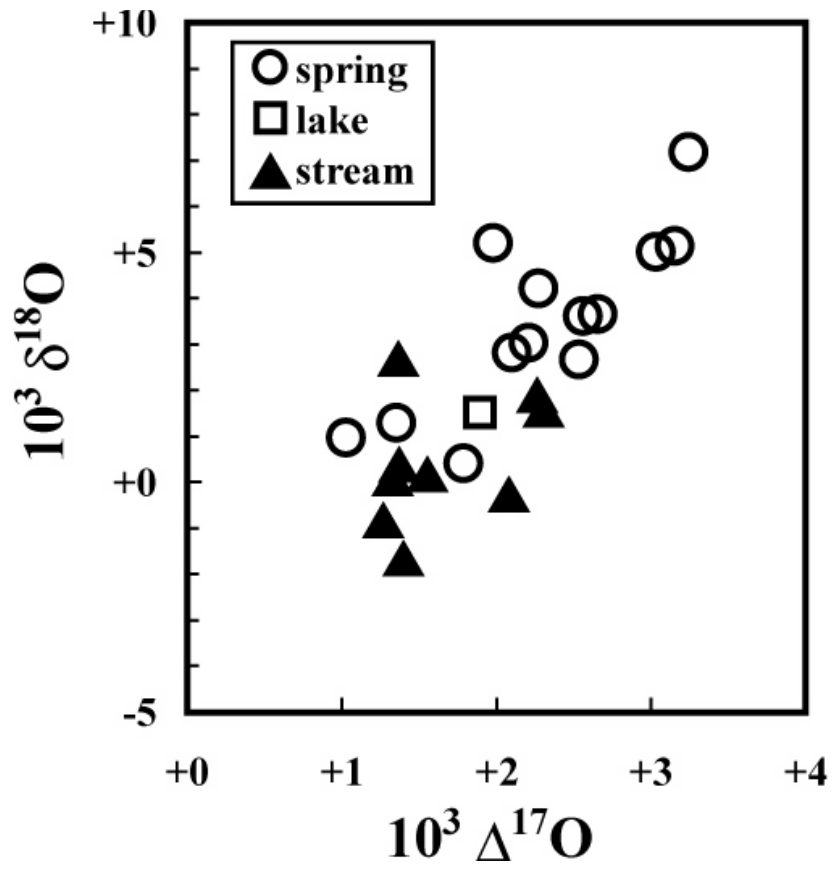

Fig. 6. Relation between $\Delta^{17} \mathrm{O}$ and $\delta^{18} \mathrm{O}$ in $\mathrm{NO}_{3}^{-}$from spring (white circles), lake (white square), and stream (black triangles) water. The symbols are the same as those in Fig. 5.

through isotopic fractionation during post-depositional processes within the forest ecosystem. To evaluate the extent of fractionation, the $\delta^{18} \mathrm{O}$ of groundwater is plotted as a function of $\Delta^{17} \mathrm{O}$ (Fig. 6). There is a linear correlation with $r^{2}=0.63$. By extrapolating the least-square-fitted line to the region of $\mathrm{NO}_{3}^{-}(\mathrm{atm})$ having $\Delta^{17} \mathrm{O}=+26.2 \%$, we obtain $\delta^{18} \mathrm{O}=(+80 \pm 26) \%$, which corresponds to values for $\mathrm{NO}_{3}^{-}(\mathrm{atm})\left(+87.1 \%\right.$ ) , in the island. We conclude the $\delta^{18} \mathrm{O}$ values primarily reflect the contribution of $\mathrm{NO}_{3}^{-}(\mathrm{atm})$ as well. While the $\delta^{18} \mathrm{O}$ values vary through isotopic fractionation during post-depositional processing such as partial removal through assimilation or denitrification, the range of variation was small on the island. The result is somewhat different from that obtained in a previous study conducted in southern California, where there was no clear linear correlation between $\Delta^{17} \mathrm{O}$ and $\delta^{18} \mathrm{O}$ for stream nitrate (Michalski et al., 2004). Each forest ecosystem has its different characteristics for post-depositional processes and we can evaluate the extent of the post-depositional alternation in $\delta^{18} \mathrm{O}$ of $\mathrm{NO}_{3}^{-}$ through assimilation and denitrification from the dispersion in the $\Delta^{17} \mathrm{O}-\delta^{18} \mathrm{O}$ plot.

On the other hand, we can obtain the $\delta^{18} \mathrm{O}$ value of $(-4.2 \pm 2.4) \% 0$ as the intercept $\left(\Delta^{17} \mathrm{O}=0\right)$ of the plot in Fig. 6. The value corresponds to the average $\delta^{18} \mathrm{O}$ value of remineralized nitrate produced through nitrification in the forest ecosystem. The remineralized nitrate in the marine environment has $\delta^{18} \mathrm{O}$ values similar to that of ambient water (sea water) of close to $0 \%$ owing to the exchange of oxy- gen atoms between nitrification intermediates and the ambient water during nitrification (Casciotti et al., 2002). On the contrary, the present results suggest that the remineralized nitrate have $\delta^{18} \mathrm{O}$ values substantially larger than those of the groundwater $\left(\delta^{18} \mathrm{O}=(-13 \pm 1) \%\right.$ o $)$ within the island, probably owing to the contribution of oxygen atoms from oxygen molecules $\left(\mathrm{O}_{2}\right)$ having $\delta^{18} \mathrm{O}$ values of $+23.88 \%$ o (Barkan and Luz, 2005) or more during nitrification in the forest soil. The exchange of oxygen atoms between nitrification intermediates and the ambient water is limited by some environmental conditions (Kool et al., 2007).

\subsection{Removal flux of atmospheric nitrate through the forest ecosystem}

Yamaguchi et al. (1975) estimated that $1.68 \times 10^{8} \mathrm{~m}^{3}$ of groundwater emerges around the shore area of the island as either terrestrial springs or submarine discharges on the basis of an extensive hydrological survey on the water cycle of the island. Our present $\Delta^{17} \mathrm{O}$ results show that the groundwater on Rishiri contains $(1.2 \pm 0.6) \mu \mathrm{mol} / \mathrm{l}$ of $\mathrm{NO}_{3}^{-}(\mathrm{atm})$ on average (Fig. 5 and Table 1). Assuming the same average $\mathrm{NO}_{3}^{-}(\mathrm{atm})$ content for all the springs on the island irrespective of whether they are terrestrial or submarine, we can estimate the direct drainage flux of $\mathrm{NO}_{3}^{-}(\mathrm{atm})$ through the forest ecosystem on Rishiri to be $(2.0 \pm 1.1) \times 10^{5} \mathrm{~mol} \mathrm{a}^{-1}$.

On the other hand, the Rishiri National Acid Rain Monitoring Station quantified the annual deposition rate of $\mathrm{NO}_{3}^{-}(\mathrm{atm})$ as $12.7 \mathrm{mmol} \mathrm{m}^{-2} \mathrm{a}^{-1}$ (average total deposition rate from 2000 to 2007), which corresponds to a total deposition rate of $\mathrm{NO}_{3}^{-}(\mathrm{atm})$ of $2.3 \times 10^{6} \mathrm{~mol} \mathrm{a}^{-1}$ on the island (EANET, 2008). Thus, the direct drainage of $\mathrm{NO}_{3}^{-}(\mathrm{atm})$ through the forest ecosystem on Rishiri corresponds to $(8.8 \pm 4.6) \%\left((1.1 \pm 0.6) \mathrm{mmol} \mathrm{m}^{-2} \mathrm{a}^{-1}\right)$ of the total $\mathrm{NO}_{3}^{-}(\mathrm{atm})$ that deposited onto the island, and the residual nitrate (ca. $90 \%$ or ca. $11.6 \mathrm{mmol} \mathrm{m}^{-2} \mathrm{a}^{-1}$ ) was removed by plants or microbes before being exported from the forest ecosystem into the groundwater.

The present estimation did not include the increasing depositional flux of $\mathrm{NO}_{3}^{-}(\mathrm{atm})$ in eastern Asia. Because the residence times were from 5 to 40 years for the groundwater within the island, the direct drainage ratio could be the minimum value since the deposition rate could be less on days when $\mathrm{NO}_{3}^{-}(\mathrm{atm})$ in spring water was deposited (Akimoto, 2003). The present depositional flux of fixed-N on Rishiri $\left(4.5 \mathrm{~kg} \mathrm{ha}^{-1} \mathrm{a}^{-1}\right)$, however, is still one of the lowermost depositional fluxes in the area around the Japan islands (EANET, 2008), probably because the island located outside of the major outflows from megacities in eastern Asia. In addition, the Rishiri National Acid Rain Monitoring Station found little evidence for an increasing trend in the nitrate deposition rate from 2000 to 2007 . Thus, we used the present depositional flux in our estimation without any corrections. 
By adding ${ }^{15} \mathrm{~N}$-labeled nitrogen $\left({ }^{15} \mathrm{NH}_{4}^{15} \mathrm{NO}_{3}\right.$ or $\mathrm{Na}^{15} \mathrm{NO}_{3}$ ) for a duration of 9 to 12 months in European coniferous forest ecosystems, Tietema et al. (1998) found drainage losses of fixed nitrogen increased as a function of the fixed-nitrogen input. They estimated the drainage accounts for 2 to $35 \%$ of the total fixed-nitrogen input under a fixed-N input condition of less than $30 \mathrm{~kg} \mathrm{ha}^{-1} \mathrm{a}^{-1}$. The estimated direct drainage of $\mathrm{NO}_{3}^{-}(\mathrm{atm})$ through the forest ecosystem on Rishiri corresponds to the lower region of the variation range estimated using ${ }^{15} \mathrm{~N}$ tracer. When using ${ }^{15} \mathrm{~N}$ tracer, direct drainage could be overestimated for the portion of secondary elution of ${ }^{15} \mathrm{NO}_{3}^{-}$that was once assimilated to organic nitrogen. Thus, we believe that our present value is a more reliable estimate for the direct drainage of $\mathrm{NO}_{3}^{-}(\mathrm{atm})$ under a low fixed-N input condition of less than $5 \mathrm{~kg} \mathrm{ha}^{-1} \mathrm{a}^{-1}$.

\section{Conclusions}

Nitrate in groundwater of Rishiri had the $\Delta^{17} \mathrm{O}$ values ranging from $+0.9 \%$ o to $3.2 \%$ o $(n=19)$, which corresponds to an mixing ratio of atmospheric nitrate to total nitrate of $(7.4 \pm 2.6) \%$. Comparing the inflow and outflow of atmospheric nitrate in groundwater within the island, we estimated that the direct drainage accounts for $(8.8 \pm 4.6) \%$ of atmospheric nitrate that has deposited on the island and that the residual portion has undergone biological processing before being exported from the forest ecosystem. The present estimation is a more reliable estimate for the direct drainage of $\mathrm{NO}_{3}^{-}(\mathrm{atm})$ under a low fixed-N input condition of less than $5 \mathrm{~kg} \mathrm{ha}^{-1} \mathrm{a}^{-1}$.

This study clearly demonstrates that $\Delta^{17} \mathrm{O}$ can be a powerful tracer of the fate of $\mathrm{NO}_{3}^{-}$(atm) deposited onto a forest ecosystem including those having small fixed-nitrogen input. By measuring $\Delta^{17} \mathrm{O}$ data of nitrate for water eluted from various forested watersheds, we can increase our understanding of fixed-nitrogen processing and fixed-nitrogen retention efficiencies for forested ecosystems that are subjected to atmospheric fixed-nitrogen deposition.

Acknowledgements. The authors would like to thank the Ministry of the Environment, Japan, for providing the monitoring data of the acid deposition survey. We would like to thank Kazumi Asai (Chikyu Kagaku Kenkyusho Corp.) and the other members of the 2006 expedition team on Rishiri Island for their valuable support and advice during sampling. We are grateful to the members of the Geochemistry Group, Faculty of Science, Hokkaido University for their valuable support throughout this study. We thank two anonymous reviewers for their constructive comments. The backward trajectory of the air parcel was calculated using METEX software (http://db.cger.nies.go.jp/metex/index.html) and NCEP datasets. This work was supported by a Grant-in-Aid of Scientific Research from the Ministry of Education, Culture, Sports, Science, and Technology of Japan under grant numbers 20310003, 19310007, and 20301822, the Global Environment Research Fund of the
Ministry of the Environment of Japan (RF-065), and the Showa Shell Sekiyu Foundation.

Edited by: J. Kaiser

\section{References}

Akimoto, H.: Global air quality and pollution, Science, 302, 17161719, 2003.

Alexander, B., Hastings, M. G., Allman, D. J., Dachs, J., Thornton, J. A., and Kunasek, S. A.: Quantifying atmospheric nitrate formation pathways based on a global model of the oxygen isotopic composition (delta O-17) of atmospheric nitrate, Atmos. Chem. Phys., 9, 5043-5056, 2009,

http://www.atmos-chem-phys.net/9/5043/2009/.

Asai, K., Zhang, J., Asai, K., A. K. Mandal, Mogi, K., and Hasegawa, K.: Residence time of submarine fresh groundwater discharge in Rishiri Island, north Japan: Application of groundwater age tracers of Tritium, CFCs and $\mathrm{SF}_{6}$, EOS, 89(53), AGU Fall Meeting Suppl. Abstract (H53E-1134), 2008.

Barkan, E., and Luz, B.: High precision measurements of ${ }^{17} \mathrm{O} /{ }^{16} \mathrm{O}$ and ${ }^{18} \mathrm{O} /{ }^{16} \mathrm{O}$ ratios in $\mathrm{H}_{2} \mathrm{O}$, Rapid Commun. Mass Spectrom., 19, 3737-3742, 2005.

Burns, D. A., and Kendall, C.: Analysis of $\delta^{15} \mathrm{~N}$ and $\delta^{18} \mathrm{O}$ to differentiate $\mathrm{NO}_{3}^{-}$sources in runoff at two watersheds in the Catskill Mountains of New York, Water Resour. Res., 38, 1051, doi:10.1029/2001WR000292, 2002.

Campbell, D. H., Kendall, C., Chang, C. C. Y., Silva, S. R., and Tonnessen, K. A.: Pathways for nitrate release from an alpine watershed: Determination using $\delta^{15} \mathrm{~N}$ and $\delta^{18} \mathrm{O}$, Water Resour. Res., 38, 1052, doi:10.1029/2001WR000294, 2002.

Casciotti, K. L., Sigman, D. M., Galanter Hastings, M., Böhlke, J. K., and Hilkert, A.: Measurement of the oxygen isotopic composition of nitrate in seawater and freshwater using the denitrifier method, Anal. Chem., 74, 4905-4912, 2002.

Duce, R. A., LaRoche, J., Altieri, K., Arrigo, K. R., Baker, A. R., Capone, D. G., Cornell, S., Dentener, F., Galloway, J., Ganeshram, R. S., Geider, R. J., Jickells, T., Kuypers, M. M., Langlois, R., Liss, P. S., Liu, S. M., Middelburg, J. J., Moore, C. M., Nickovic, S., Oschlies, A., Pedersen, T., Prospero, J., Schlitzer, R., Seitzinger, S., Sorensen, L. L., Uematsu, M., Ulloa, O., Voss, M., Ward, B., and Zamora, L.: Impacts of Atmospheric Anthropogenic Nitrogen on the Open Ocean, Science, 320, $893-$ 897, 2008.

Durka, W., Schulze, E.-D., Gebauer, G., and Voerkeliust, S.: Effects of forest decline on uptake and leaching of deposited nitrate determined from ${ }^{15} \mathrm{~N}$ and ${ }^{18} \mathrm{O}$ measurements, Nature, 372 , 765-767, 1994.

EANET: Data Report 2007, Network center for EANET (Acid Deposition Monitoring Network in East Asia), Nigata, Japan, 229 pp., 2008.

Fenn, M. E., Poth, M. A., Aber, J. D., Baron, J. S., Bormann, B. T., Johnson, D. W., Lemly, A. D., McNulty, S. G., Ryan, D. F., and Stottlemyer, R.: Nitrogen excess in north American ecosystems: Predisposing factors, ecosystem responses, and management strategies, Ecol. Appl., 8, 706-733, 1998.

Galloway, J. N., Townsend, A. R., Erisman, J. W., Bekunda, M., Cai, Z., Freney, J. R., Martinelli, L. A., Seitzinger, S. P., and Sutton, M. A.: Transformation of the Nitrogen Cycle: Recent 
Trends, Questions, and Potential Solutions, Science, 320, 889892, 2008.

Grennfelt, P., and Hultberg, H.: Effects of nitrogen deposition on the acidification of terrestrial and aquatic ecosystems, Water Air Soil Poll., 30, 945-963, 1986.

Guttikunda, S. K., Tang, Y. H., Carmichael, G. R., Kurata, G., Pan, L., Streets, D. G., Woo, J. H., Thongboonchoo, N., and Fried, A.: Impacts of Asian megacity emissions on regional air quality during spring 2001, J. Geophys. Res., 110, D20301, doi:10.1029/2004jd004921, 2005.

Haruki, M., Fujiwara, A., Matsuda, K., Natsume, S., Yajima, T., Namikawa, K., and Niiyama, K.: Forest vegetation in Rishiri and Rebun Islands in Hokkaido, Japan, (in Japanese with English abstract), Rishiri Studies, 23, 27-91, 2004.

Hayashi, T., Marui, A., and Yasuhara, M.: Characteristics of water chemistry of inland water and submarine discharged groundwater in Rishiri island, northern Japan, (in Japanese), J. Jpn. Assoc. Hydrol. Sci., 29, 123-138, 1999.

Ijiri, A., Tsunogai, U., and Gamo, T.: Simple method for oxygen18 determination of milligram quantities of water using $\mathrm{NaHCO}_{3}$ reagent, Rapid Commun. Mass Spectrom., 17, 1472-1478, 2003.

Kaiser, J., Hastings, M. G., Houlton, B. Z., Röckmann, T., and Sigman, D. M.: Triple oxygen isotope analysis of nitrate using the denitrifier method and thermal decomposition of $\mathrm{N}_{2} \mathrm{O}$, Anal. Chem., 79, 599-607, 2007.

Komatsu, D. D., Ishimura, T., Nakagawa, F., and Tsunogai, U.: Determination of the ${ }^{15} \mathrm{~N} /{ }^{14} \mathrm{~N},{ }^{17} \mathrm{O} /{ }^{16} \mathrm{O}$, and ${ }^{18} \mathrm{O} /{ }^{16} \mathrm{O}$ ratios of nitrous oxide by using continuous-flow isotope-ratio mass spectrometry, Rapid Commun. Mass Spectrom., 22, 1587-1596, 2008.

Kool, D. M., Wrage, N., Oenema, O., Dolfing, J., and Van Groenigen, J. W.: Oxygen exchange between (de)nitrification intermediates and $\mathrm{H}_{2} \mathrm{O}$ and its implications for source determination of $\mathrm{NO}_{3}^{-}$and $\mathrm{N}_{2} \mathrm{O}$ : a review, Rapid Commun. Mass Spectrom., 21, 3569-3578, doi:10.1002/rcm.3249, 2007.

Marui, A., Yasuhara, M., and Hayashi, T.: Visit to valuable water springs (46) Valuable water springs on Rishiri island in Hokkaido, Japan: Kanrozen spring and submarine groundwater discharge, (in Japanese), Jour. Jap. Assoc. Groundwater Hydrol., 41, 213-220, 1999.

Marui, A.: Groundwater conditions along the seawater/freshwater interface on a volcanic island and a depositional area in Japan, Geol. Quart., 47, 381-388, 2003.

McIlvin, M. R. and Altabet, M. A.: Chemical Conversion of nitrate and nitrite to nitrous oxide for nitrogen and oxygen isotope analysis in Freshwater and seawater, Anal. Chem., 77, 5589-5595, 2005.

Michalski, G., Savarino, J., Böhlke, J. K., and Thiemens, M.: Determination of the total oxygen isotopic composition of nitrate and the calibration of a $\Delta^{17} \mathrm{O}$ nitrate reference material, Anal. Chem., 74, 4989-4993, 2002.

Michalski, G., Scott, Z., Kabiling, M., and Thiemens, M. H.: First measurements and modeling of $\Delta^{17} \mathrm{O}$ in atmospheric nitrate, Geophys. Res. Lett., 30, 1870, doi:10.1029/2003GL017015, 2003.

Michalski, G., Meixner, T., Fenn, M., Hernandez, L., Sirulnik, A., Allen, E., and Thiemens, M.: Tracing Atmospheric Nitrate Deposition in a Complex Semiarid Ecosystem Using $\Delta^{17} \mathrm{O}$, Environ. Sci. Technol., 38, 2175-2181, 2004.
Miller, M. F.: Isotopic fractionation and the quantification of ${ }^{17} \mathrm{O}$ anomalies in the oxygen three-isotope system: an appraisal and geochemical significance, Geochim. Cosmochim. Acta, 66, 1881-1889, 2002.

Ministry of the Environment: Report on Long-term Acid Deposition Monitoring (FY2003-2007), (in Japanese), Ministry of the Environment, 2009.

Morin, S., Savarino, J., Frey, M. M., Yan, N., Bekki, S., Bottenheim, J. W., and Martins, J. M. F.: Tracing the Origin and Fate of $\mathrm{NO}_{\mathrm{X}}$ in the Arctic Atmosphere Using Stable Isotopes in Nitrate, Science, 322, 730-732, 10.1126/science.1161910, 2008.

Morin, S., Savarino, J., Frey, M. M., Domine, F., Jacobi, H. W., Kaleschke, L., and Martins, J. M. F.: Comprehensive isotopic composition of atmospheric nitrate in the Atlantic Ocean boundary layer from 65 degrees S to 79 degrees N, J. Geophys. Res., 114, D05303, doi:10.1029/2008jd010696, 2009.

Murdoch, P. S. and Stoddard, J. L.: The Role of Nitrate in the Acidification of Streams in the Catskill Mountains of New York, Water Resour. Res., 28, 2707-2720, 1992.

Noguchi, I., Hayashi, K., Aikawa, M., Ohizumi, T., Minami, Y., Kitamura, M., Takahashi, A., Tanimoto, H., Matsuda, K., and Hara, H.: Temporal trend of non-sea salt sulfate and nitrate in wet deposition in Japan, Water, Air, and Soil Pollution: Focus, 7, 67-75, 2007.

Ohte, N., Sebestyen, S. D., Shanley, J. B., Doctor, D. H., Kendall, C., Wankel, S. D., and Boyer, E. W.: Tracing sources of nitrate in snowmelt runoff using a high-resolution isotopic technique, Geophys. Res. Lett., 31, L21506, doi:10.1029/2004GL020908, 2004.

Paerl, H. W.: Coastal eutrophication and harmful algal blooms: Importance of atmospheric deposition and groundwater as "new" nitrogen and other nutrient sources, Limnol. Oceanogr., 42, 1154-1165, 1997.

Tanimoto, H., Kajii, Y., Hirokawa, J., Akimoto, H., and Minko, N. P.: The atmospheric impact of boreal forest fires in far eastern Siberia on the seasonal variation of carbon monoxide: Observations at Rishiri, a northern remote island in Japan, Geophys. Res. Lett., 27, 4073-4076, 2000.

Tietema, A., Emmett, B. A., Gundersen, P., Kjonaas, O. J., and Koopmans, C. J.: The fate of N-15-labelled nitrogen deposition in coniferous ecosystems, Forest Ecol. Manag., 101, 19-27, 1998.

Tilman, D., Wedin, D., and Knops, J.: Productivity and sustainability influenced by biodiversity in grassland ecosystems, Nature, 379, 718-720, 1996.

Tsunogai, U. and Wakita, H.: Precursory chemical changes in ground water: Kobe earthquake, Japan, Science, 269, 61-63, 1995.

Tsunogai, U., Nakagawa, F., Komatsu, D. D., and Gamo, T.: Stable carbon and oxygen isotopic analysis of atmospheric carbon monoxide using continuous-flow isotope ratio MS by isotope monitoring of CO, Anal. Chem., 74, 5695-5700, 2002.

Tsunogai, U., Nakagawa, F., Gamo, T., and Ishibashi, J.: Stable isotopic compositions of methane and carbon monoxide in the Suiyo hydrothermal plume, Izu-Bonin arc: tracers for microbial consumption/production, Earth Planet. Sci. Lett., 237, 326-340, 2005.

Tsunogai, U., Kido, T., Hirota, A., Ohkubo, S. B., Komatsu, D. D., and Nakagawa, F.: Sensitive determinations of stable nitrogen 
isotopic composition of organic nitrogen through chemical conversion into $\mathrm{N}_{2} \mathrm{O}$, Rapid Commun. Mass Spectrom., 22, 345354, 2008.

Uno, I., Uematsu, M., Hara, Y., He, Y. J., Ohara, T., Mori, A., Kamaya, T., Murano, K., Sadanaga, Y., and Bandow, H.: Numerical study of the atmospheric input of anthropogenic total nitrate to the marginal seas in the western North Pacific region, Geophys. Res. Lett., 34, L17817, doi:10.1029/2007GL030338,032007.030309, 2007.

Williams, M. W., Baron, J. S., Caine, N., Sommerfeld, R., and Sanford, R.: Nitrogen Saturation in the Rocky Mountains, Environ. Sci. Technol., 30, 640-646, 1996.

Williard, K. W. J., DeWalle, D. R., Edwards, P. J., and Sharpe, W. E.: ${ }^{18} \mathrm{O}$ isotopic separation of stream nitrate sources in mid-Appalachian forested watersheds, J. Hydrol., 252, 174-188, 2001.
Yamaguchi, H. and Ohara, T.: Groundwater in Rishiri Island, Hokkaido: No. 1, (in Japanese), Jour. Jap. Soc. Eng. Geol., 12, 109-120, 1971.

Yamaguchi, H.: Hydrologic balance in the Island of Rishiri, Rep. Geol. Survey Hokkaido, (in Japanese with English abstract), 47, 1-21, 1975.

Zeng, J., Tohjima, Y., Fujinuma, Y., Mukai, H., and Katsumoto, M.: A study of trajectory quality using methane measurements from Hateruma Island, Atmos. Environ., 37, 1911-1919, 2003.

Zhang, X. Y., Zhang, P., Zhang, Y., Li, X. J., and Qiu, H.: The trend, seasonal cycle, and sources of tropospheric $\mathrm{NO}_{2}$ over China during 1997-2006 based on satellite measurement, Science in China, Ser. D, 50, 1877-1884, 2007. 